\title{
De Marne 1914 a Marne 1918: as grandes batalhas da Primeira Guerra Mundial
}

\author{
From Marne 1914 to Marne 1918: the great battles of World War \\ De Marne 1914 Marne 1918: las grandes batallas de la Primera Guerra Mundial
}

Wojciech Skrzątek $^{*}$

\section{Resumo}

A Primeira Guerra Mundial foi a primeira guerra total contemporânea. Diferentemente dos conflitos anteriores, em que predominavam as operações de manobras, agora as operações bélicas duravam meses ou até anos e produziam milhões de vítimas. Os exércitos necessitavam de cada vez mais gente, de cada vez mais armas - e isso só podia ser obtido à custa da sociedade, de maneira que a guerra atingia a quase todas as famílias.

Palavras-chave: Primeira Guerra Mundial. Marne. Tannenberg. Batalha da Jutlândia. Somme. Verdun.
Desde 1871, ou seja, desde o encerramento da guerra com a França, no estado-maior alemão existia a forte convicção de que a guerra seguinte que a Alemanha travaria seria uma guerra em duas frentes: com a França e com a Rússia. Esse era também o desenrolar dos acontecimentos previsto pelo plano estratégico preparado pelo chefe do estado-maior, general Alfred von Schlieffen

\footnotetext{
Graduado pela Universidade de Varsóvia (1991 Mestre em História) e em estudos de pós-graduação na área de administração (Departamento de Administração). Em junho de 2006 defendeu a tese de doutorado. Em 2014 obteve, no Departamento de Letras Modernas da Universidade de Varsóvia, o título de Doutor Livre Docente na área de Estudos Literários. Desde 2006 - diretor da Sociedade Científico-Cultural Popular em Varsóvia. E-mail: w.skrzatek@gmail.com
}

Recebido em 01/10/2014 - Aprovado em 10/10/2014 http://dx.doi.org/10.5335/hdtv.14n.2.4572 
(1833-1913), elaborado nos anos 1891-1905. A França devia ser dominada rapidamente, e depois todas as forças alemãs deviam ser lançadas à frente russa. $\mathrm{O}$ realizador desse plano foi o sucessor de Shlieffen, o general Helmuth von Moltke (1848-1916). Na França, desde a memorável guerra com a Alemanha nos anos 1870-1871, não se pensava em ações ofensivas, mas em ações defensivas. Ao longo da fronteira com a Alemanha, surgiu uma linha de fortificações de defesa. Somente em 1911, surgiram mudanças significativas na doutrina de guerra francesa. $\mathrm{O}$ chefe do estado-maior, general Joseph Joffre (1852-1931), assumiu a norma da passagem a uma imediata e absoluta ofensiva, em grande medida na fronteira com a Alemanha.

Uma prova de realização dessa concepção foi o ataque dos franceses, dirigido no dia 7 de agosto de 1914 contra a Alsácia, anexada em 1871 ao Reich Alemão. Esse ataque não produziu os esperados efeitos, mas, nas consequências, o seu significado para Paris mostrou ser favorável. Os alemães encaminharam à Alsácia uma parte das divisões de reserva que primitivamente deviam fortalecer o ataque principal. Sem dúvida obtiveram um sucesso tático, mas o objetivo - que era a destruição do exército francês - não foi atingido. Os alemães queriam assegurar isso graças a uma manobra de envolvimento por meio da neutra Bélgica, de acordo com o plano de Schieffen. A seguir, os exércitos alemães deviam envolver Paris do oeste e atacar por trás o exército francês, concentrado na fortificada fronteira franco-alemã, e depois destruí-lo por completo.

A manobra de envolvimento dos alemães não surpreendeu o comando francês.
Eles se defrontaram com a resistência, não apenas da parte dos franceses, mas também do corpo expedicionário britânico - da British Expeditionary Force, que contava quatro divisões de infantaria e uma de cavalaria. A presença dos britânicos fortaleceu o moral dos franceses e a sua fé na vitória, porquanto esses não sabiam que o ministro da guerra britânico, Lord Horatio Kitchener (1850-1916), numa instrução ao comandante do corpo - John D. P. French (1852-1925), conclamava à moderação, escrevendo:

Embora o Senhor deva empenhar-se diligentemente por adaptar-se aos pontos de vista e aos desejos dos nossos aliados [...], peço-lhe que se lembre de que o Senhor é plenamente independente e nunca, em nenhum caso e em nenhum significado, se encontrará sob o comando do general aliado. ${ }^{1}$

A coalizão dos exércitos franco-britânicos não deteve o ataque nas forças alemãs na foz dos rios Somme e Oise. No dia 25 de agosto, o comandante francês Joffre ordenou a retirada. Esse admirador de Napoleão e leitor de Clausewitz nos momentos mais difíceis era, no entanto, capaz de manter os nervos sob controle. Quando se deu conta de que seus planos haviam falhado, de que tinha perdido a primeira batalha, decidiu retirar-se metodicamente, de forma a não permitir a desorganização do exército. Os exércitos franco-ingleses retiraram-se para o outro lado do rio Marne, a leste de Paris, e ficaram aguardando o momento adequado de passar à contraofensiva. Enquanto isso, os alemães avançavam, mas não foram capazes de envolver as forças aliadas. Além disso, no final de agosto e início de setembro Moltke, que residia em Luxemburgo, em razão de problemas de comunicação, perdeu a orien- 
tação quanto à situação na linha de frente. Em razão da ofensiva russa na Prússia Oriental, removeu para aquela frente dois corpos, e algumas divisões foram envolvidas na conquista de fortalezas no território da Bélgica. A ofensiva alemã perdeu o seu primitivo caráter planejado e foi adquirindo traços de casualidade.

Nessa situação, a relação de forças na frente, de Paris até Verdun, no início de setembro mudou a favor dos exércitos franco-britânicos (56 divisões de infantaria e dez divisões de cavalaria, 1. 082 mil soldados, 2. 816 de peças de artilharia leves e 184 pesadas), contra os alemães (44 divisões de infantaria e sete divisões de cavalaria, $900 \mathrm{mil}$ soldados, 2. 928 peças de artilharia leves e 436 pesadas). Nessa situação, os franceses decidiram-se pela contraofensiva, que começou no dia seis de setembro e durou quatro dias. Nessa obstinada batalha, definida pela História como a primeira batalha do Marne, mostraram-se melhores os franceses. Diante da ameaça do envolvimento e do extermínio de um dos seus exércitos, os alemães se retiraram. Detiveram-se nas margens do rio Aisne. A contraofensiva francesa, apesar de não ter conseguido repelir o inimigo para além das fronteiras da França, terminou em vitória.

Após dois meses de encarniçadas lutas, a frente de batalha estabeleceu-se ao longo de uma dupla linha de trincheiras, estendendo-se pela França, desde a Suíça até o Canal da Mancha. Iniciou-se uma longa e exterminadora guerra de posições. Essa linha era formada por filas de trincheiras, abrigos e abatis de arame farpado. A defesa predominava sobre o ataque. Tais fortifica- ções não podiam ser obtidas sem o fogo da artilharia. A guerra de posições, num caso de equilíbrio de forças, não podia levar à vitória de nenhuma das partes. Somente em 1918 o predomínio numérico e armado dos Estados aliados levou ao rompimento com a concepção, até então adotada de operações bélicas, e permitiu passar a uma guerra ofensiva contra a Alemanha.

A batalha do Marne foi um ponto crucial na história da Primeira Guerra Mundial. A derrota da Alemanha impossibilitou-lhe a rápida vitória sobre a França, eliminou as possibilidades de uma guerra de curta duração e abriu o caminho a uma guerra longa, de mais de quatro anos. A culpa pelo insucesso na realização de uma guerra relâmpago coube a von Moltke, que no dia 14 de setembro foi destituído pelo imperador Guilherme II. Para o seu lugar foi indicado o ministro da guerra prussiano Erich von Falkenhayn (1861-1922). Para manter as aparências e com o objetivo de não permitir que a sociedade pensasse em derrota, a nomeação de von Falkenhayn só foi anunciada no dia 3 de novembro de 1914.

Naquele tempo, enquanto os alemães conquistavam a Bélgica, e antes ainda do término final da mobilização, moveram uma ofensiva contra eles os russos. O seu ataque foi encaminhado contra a Prússia Ducal (que se estendia do Vístula ao Niemen). A frente noroeste era comandada pelo general de cavalaria Yakov Zhilinski (1853-1918) e era formada de dois exércitos: 1 . do exército sob o comando do general de cavalaria Paul von Rennenkampf (1854-1918) e 2. do exército sob o comando do general de cavalaria Aleksandr Samsonov (1859-1914). O 
objetivo da operação russa na Prússia Ducal era destruir os exércitos alemães que ali se encontravam e garantir a segurança aos territórios ocidentais do Império Russo e ao exército russo envolvido na ação contra a Áustria-Hungria.

$\mathrm{Na}$ guerra em duas frentes, para a defesa da Prússia Ducal a Alemanha podia destinar pequenas forças - apenas o $8^{\circ}$ exército, comandado pelo general Max von Prittwitz und Gaffron (1848-1917). Essas áreas não tinham para Berlim o mesmo significado que a Renânia, a Vestfália ou a Silésia. A Alemanha contava até com a temporária perda da Prússia Ducal. Apesar disso, tinha a esperança de que o formato geográfico do país - florestas e lagos, além de uma bem desenvolvida rede de estradas e ferrovias - possibilitaria ações de caráter defensivo-ofensivo.

Já a 17 de agosto de 1914, o primeiro a entrar no território alemão foi o exército de Rennenkampf. Após alguns dias de marcha, o seu caminho foi cortado pelas forças alemãs, que na batalha de Gabin (Gąbin) sofreram grandes perdas. Diante disso, Prittwitz, temendo o envolvimento pelo exército de Samsonov, ordenou a retirada dos exércitos alemães. O pânico que se estabeleceu entre os influentes fazendeiros locais e a real perspectiva da perda do berço do Estado prussiano fizeram com que o comando-chefe alemão destituísse o chefe do $8^{\circ}$ exército - o psiquicamente frágil Prittwitz. Para o seu lugar foi chamado o velho general Paul von Hindenburg (1947-1934), temperado em muitas batalhas, e para a chefia do seu estado-maior - Erich Ludendorff (1865-1937). A respeito desse, após alguns dias de coope- ração, o tenente-coronel Max Hoffmann escreveu: "Para as tarefas locais ele é a pessoa adequada, com o seu incrível rigor e a sua grosseria". 2

A 23 de agosto, isso é, no dia em que o general Hindenburg e o general Ludendorff vieram a Malbork, o $2^{\circ}$ exército russo entrou na linha de ataque em direção a Olsztyn, o que aconteceu em razão de informações erradas a respeito da situação na linha de frente. Com efeito, o general Samsonov, convencido da derrota dos exércitos alemães e das operações ativas do exército do general Rannenkampf, desviou para cerca de 30 quilômetros a oeste a direção do ataque, querendo definitivamente cortar ao $8^{\circ}$ exército o caminho de volta para a outra margem do Vístula. Entre os exércitos russos, surgiu uma perigosa lacuna, que atingia a extensão de mais de 120 quilômetros. O comandante do $2^{\circ}$ exército estava convencido de que não se estava dirigindo para uma batalha importante com um adversário organizado, mas de que a sua tarefa era apenas impedir a retirada de exércitos já vencidos, desorganizados e desmoralizados. Além da inação do exército do general Rannenkampf, foi justamente isso que motivou a sua decisão de desviar a frente mais para o oeste. Não deixava de ser significativo também o fato de que os alemães conheciam os planos operacionais dos russos, que haviam conseguido de um alto oficial do exército do general Samsonov por eles feito prisioneiro.

Nessa situação, o general Hindenburg decidiu flanquear, e a seguir - nas lutas que se estenderam de 26 a 31 de agosto - destroçar completamente o exército do general Samsonov em Tannenberg. A maior parte 
do exército russo (cerca de 120 mil soldados, isso é, $75 \%$ do contingente do exército) foi feita prisioneira. $\mathrm{O}$ próprio comandante, o general Samsonov, suicidou-se. O motivo da derrota não foram apenas os problemas de comunicação, mas também a falta de coordenação das ações entre ambos os exércitos russos, porquanto não era segredo que ambos os generais não se viam com simpatia (acusavam-se mutuamente de incompetência e nutriam ressentimentos ainda dos tempos da guerra russo-japonesa), o que impossibilitava coordenação das ações e a colaboração.

Alguns dias depois Hindenburg decidiu acertar as contas com o exército do general Rennenkampf, apesar de os exércitos russos terem supremacia numérica sobre os alemães. A tarefa desses foi facilitada pelo próprio comandante russo: "A inação de Rennenkampf - escrevia o general Michaelis (1863-1939 - tinha um nítido caráter de traição". ${ }^{3} \mathrm{Na}$ realidade o formato do terreno e as forças insuficientes não permitiram aos alemães envolver o inimigo e pinçá-lo, mas mesmo assim conseguiram garantir a supremacia. A batalha se estendeu de 8 a 15 de setembro. A derrota de Rannenkampf foi esmagadora: setenta mil mortos e feridos, 45 mil aprisionados e 150 peças de artilharia perdidas.

As operações de guerra na Prússia Ducal tiveram sérias consequências e em certo sentido contribuíram para a derrota da Alemanha na frente ocidental. Com efeito, no dia 26 de agosto o general Moltke retirou da França e enviou para a frente oriental dois corpos alemães, que na realidade não conseguiram chegar a Tannenberg e, além disso, fizeram falta no momento da ofensiva decisiva no ocidente - nas margens do Marne. Assim avaliavam esses acontecimentos também os russos: "Estamos felizes porque pudemos sofrer tal sacrifício pelos nossos aliados" - respondeu o comandante-chefe russo, o arquiduque Nikolay Nikolayevich (1856-1929), ao adido militar francês que lhe apresentava condolências em razão da derrota. Ao pronunciar essas palavras, ele certamente não se dava conta de que a derrota na Prússia foi um sensível desastre não apenas para a Rússia, mas também para o tsarismo. Nos campos prussianos, pereceram ou foram aprisionados os oficiais mais fiéis ao tsar. O enfraquecimento desse elemento nas primeiras batalhas pesou profundamente nas futuras operações de guerra e na posição do tsarismo.

A estagnação que se estabeleceu na frente ocidental induzia a direção política e militar da Coalizão à busca de novos métodos eficazes de condução da guerra. Os políticos franceses afirmavam, na realidade, que a guerra seria decidida no ocidente, mas Londres buscava febrilmente caminhos de saída do impasse. Surgiu a ideia de que, visto que não havia chances de vitória num embate com o inimigo principal, era preciso criar uma nova frente, de preferência com o elo mais frágil da coalizão dos estados centrais. Como tal elo foi reconhecido o Império Otomano, que desde o início da Primeira Guerra Mundial se havia colocado ao lado da Alemanha e da Áustria-Hungria, contando que - após a vitória sobre os Estados centrais - recuperaria as terras perdidas ainda no Século XIX em favor da Rússia. 
No entanto, a Turquia tinha um trunfo importante na manga - controlava os estratégicos estreitos do Mar Negro, que, após entrar no conflito, imediatamente fechou. Por isso, a Rússia ficou praticamente isolada do mundo, visto que o Mar Báltico era controlado pela poderosa frota alemã. Em tais circunstâncias, no comando dos aliados surgiu um plano que devia ajudar aos russos e eliminar os turcos da guerra. No dia 28 de janeiro de 1915, o Conselho de Guerra britânico ordenou uma "expedição marítima [...] para bombardear a península de Gallipoli, tendo Constantinopla como o objetivo final". ${ }^{4}$ De fato, a conquista de Constantinopla abriria o caminho à Rússia, permitiria que lhe fossem fornecidas as necessárias munições e armas e, em troca, que da Ucrânia fosse importado o trigo. A Grã-Bretanha estava também interessada em fortalecer a sua posição no Oriente Médio, sobretudo no Egito. Esperava-se também que se colocariam a favor da Coalizão três países até então neutros - a Grécia, a Bulgária e a Romênia. Os planos ingleses pressupunham que a marinha britânica isolaria do restante do país os exércitos turcos que se encontravam na península de Gallipoli, o que provocaria na Turquia uma revolução e a mudança do governo em Constantinopla. ${ }^{5}$ Esses cálculos, o que mostrou o futuro próximo, não deram muito certo. Em fevereiro de 1915, a Alemanha concedeu à Bulgária um importante empréstimo, o que em consequência levou esse país a aderir ao bloco dos Estados centrais. Por sua vez, à participação da Grécia no ataque contra Constantinopla opôs-se a Rússia, a qual nutria o receio de que os gregos poderiam exigir a anexação da antiga Bizâncio à grande Grécia.
As operações armadas iniciaram-se no dia 19 de fevereiro de 1915. A poderosa frota franco-britânica (17 navios de linha, seis cruzadores, 22 contratorpedeiros, nove submarinos, 24 caça-minas) tentou entrar no Mar de Mármara. Após sofrer pesadas perdas num dos campos minados no estreito de Dardanelos, no dia 22 de maio o comando inglês proclamou que a conquista dos estreitos exclusivamente com forças marítimas era impossível. Postulava-se a introdução na luta de forças terrestres, que deviam dominar a península de Gallipoli (que rodeia o estreito de Dardanelos do noroeste) e eliminar a artilharia litorânea turca. Somente então os caça-minas aliados poderiam limpar o estreito das minas e abrir aos potentes cruzadores o caminho a Istambul. Além dos exércitos britânicos e de uma divisão francesa, foram destinados à ação exércitos australianos e neozelandeses (Australian and New Zealand Army Corps - conhecidos pela sigla ANZAC). Mais de oitenta mil homens desembarcaram na região Sudoeste da península no dia 25 de abril de 1915. A península era defendida por cinco divisões turcas, comandadas por Otto Liman von Sanders (1855-1929), general de cavalaria prussiano e marechal turco. $\mathrm{O}$ ataque dos exércitos aliados não teve sucesso total, apesar de os soldados terem conseguido conquistar as cabeças de ponte e mantê-las. No lugar da rápida guerra de manobras, planejada pelo estado-maior aliado, ocorreram destruidoras batalhas posicionais dirigidas das trincheiras, a exemplo daquelas da frente ocidental. Em novembro de 1915, Lord Kitchener, após ter feito uma inspeção, chegou à conclusão de que a entrada em Dardanelos não podia 
ser forçada. No dia 9 de janeiro, terminou a campanha, que foi uma humilhante derrota da Entente e uma das últimas grandes vitórias do Império Otomano. Naquele dia, os últimos infantes britânicos abandonaram as praias da península turca de Gallipoli, que por mais de oito meses havia sido palco de sangrentas lutas de centenas de milhares de soldados. Nas lutas pereceram ou ficaram feridos - como se calcula - cerca de $150 \mathrm{mil}$ pessoas do lado da Coalizão e 250 mil do lado turco. As lutas em Dardanelos infligiram um enorme golpe à autoridade da Entente, de maneira especial à Grã-Bretanha.

Outro golpe com que em 1916 teve de se medir a Grã-Bretanha foi o insucesso na batalha naval que, na historiografia, é definida como batalha da Jutlândia ou batalha de Skagerrak. Desde a vitoriosa batalha nas ilhas Falkland, no dia 8 de outubro de 1914, a frota britânica reinava nos mares. Juntamente com a frota francesa, procurava bloquear as frotas dos Estados centrais para afastá-los das matérias-primas e da alimentação. Naquele tempo, a base da estratégia da frota alemã era evitar o embate direto com a frota britânica, considerada como a melhor do mundo. No dia 18 de janeiro de 1916, o novo comandante da Hochseeflothe (Frota do alto mar) passou a ser o vice-almirante Reinhard von Scheer (1863-1928). Contrariamente ao seu antecessor Hugo von Pohl (1855-1916), ele era um decidido partidário do confronto direto com os britânicos. Assumiu o jogo arriscado que consistia na mobilização dos submarinos, que tinham por tarefa provocar a frota britânica a sair para o mar, para ali a atacar e lhe infligir um sensível golpe. $\mathrm{O}$ resultado da nova estratégia foi a maior ba- talha naval dos tempos da Primeira Guerra Mundial, que ocorreu no dia 31 de maio de $1916 .^{6}$

Da batalha da Jutlândia participaram de ambos os lados 250 navios de diversas classes, que transportavam cerca de $105 \mathrm{mil}$ pessoas. A frota britânica, comandada pelo almirante John Jellicoe (1859-1935), dispunha de 151 unidades; a alemã, comandada pelo vice-almirante Scheer, possuía 99 delas. Igualmente, o predomínio na artilharia estava do lado dos britânicos. Na batalha da Jutlância, naufragaram 14 navios britânicos e 11 alemães, e pereceram mais de 8500 marinheiros de ambas as frotas. Ambos os lados proclamaram a sua vitória, embora nenhum deles tivesse atingido os objetivos propostos antes da batalha. O sucesso tático foi alcançado pelos alemães, que perderam menos unidades e sofreram, sensivelmente, menores perdas humanas. No entanto, a Royal Navy (Marinha Real) preservou o domínio nos mares que cercavam a Europa e a plena capacidade de manter o bloqueio econômico da Alemanha.

Enquanto isso, a Kaiserliche Marine (Marinha Imperial) mais uma vez mudou a sua estratégia. Abandonou em breve os embates com unidades de superfície, concentrando-se na ilimitada guerra submarina dirigida contra as vias comerciais britânicas, em consequência da qual, de abril a julho de 1917, os U-boots (submarinos) alemães afundaram no total navios aliados e neutros com a tonelagem de dois milhões de BRT (Brutto Register Tone). Vítimas dos submarinos de guerra alemães foram também os navios neutros brasileiros. No dia cinco de abril de 1917, a frota alemã afundou o cargueiro 
brasileiro "Paraná". Em novos bombardeios nos oceanos, foram seriamente danificados os navios brasileiros "Ipojuca" e "Lapa" (em maio), bem como "Macau" (em outubro). Como forma de desforra, desde junho a frota brasileira começou a aprisionar os navios alemães estacionados no litoral do Brasil. No dia 26 de outubro, o Congresso Nacional aprovou uma proposta do presidente Venceslau Brás (1878-1966) sobre a declaração de guerra à Alemanha. Um pouco antes - já no dia 6 de abril - haviam declarado guerra à Alemanha os Estados Unidos.

No entanto, antes que os Estados Unidos se juntassem à guerra, a Europa foi testemunha de muitas campanhas sangrentas, que acabaram indecisas. Na conferência de Chantilly, em dezembro de 1915, os comandantes das forças aliadas decidiram que no verão do ano seguinte seria preciso promover ofensivas em todas as frentes mais importantes. Na frente ocidental, nas margens do rio Somme, deviam atacar os britânicos e os franceses. No entanto, os seus planos foram prejudicados pelo ataque dos alemães em Verdun. Após os sucessos na frente oriental, os alemães decidiram atacar o Ocidente. O plano de ataque contra a bem fortificada fortaleza de Verdun, no final de 1915, foi elaborado pelo chefe do estado-maior alemão general Erich von Falkenhayn. Esse plano não era dirigido tanto contra a França como contra a sua aliada - a Grã-Bretanha, a qual - na opinião do general Fakkenhayn - devia ser vencida para ganhar a guerra. O comando alemão pretendia realizar isso, por um lado, conquistando a supremacia no mar, e - por outro lado - eliminando as forças terrestres da principal aliada da Grã-
-Bretanha - a França. O exército francês devia ser "sangrado" numa batalha travada por objetivos importantes para os franceses, tanto do ponto de vista estratégico como psicológico. Foi por isso que Falkenhayn escolheu Verdun, uma fortaleza definida como o "coração da França". ' A batalha de Verdun, defendida pelos exércitos comandados pelo general Philippe Pétain (1856-1951), foi travada de 21 de fevereiro a 20 de dezembro de 1916 (segundo outra periodização, até junho de 1916).

A batalha, que durou mais de um ano, não trouxe aos alemães sucessos territoriais nem mudanças significativas, e não levou ao colapso do exército francês. Por um lado, as lutas por Verdun tornaram-se um símbolo de heroísmo e dedicação, mas, por outro lado, definições como "o inferno de Verdun" expressavam o absurdo da guerra. Nas lutas pela fortaleza foram vitimadas perto de 700 mil pessoas (mortos, feridos, desaparecidos, prisioneiros). Do lado alemão as perdas chegaram a 337 mil soldados, do lado francês - a 362 mil. A região de Verdun foi inteiramente devastada. Os franceses na realidade comprovaram a sua força defensiva, mas ao mesmo tempo, em razão do esgotamento, perderam a capacidade de ofensiva.

O longo envolvimento francês nas lutas em Verdun fez com que o peso principal nos preparativos da operação nas margens do Somme recaísse sobre os britânicos. As lutas nas margens do Somme foram - como registrou um historiador inglês:

[...] a glória e ao mesmo tempo o cemitério do exército de Kitchener, daqueles cidadãos-voluntários que - respondendo ao apelo do ano 1914 - formaram o primeiro exército nacional da Grã-Bretanha. ${ }^{8}$ 
No dia 24 de junho de 1916, os franceses e os ingleses iniciaram intensificados preparativos da artilharia (foram lançados mais de 1,5 milhão de projéteis). Isso tinha por objetivo a destruição das fortificações alemãs, que depois - como se acreditava seria ocupadas sem maior resistência pela infantaria. O esperado colapso da posição do inimigo devia ser a seguir aproveitado pela cavalaria. Um dos objetivos da batalha era também a "sangria" do adversário e o afastamento das suas forças das outras frentes. $\mathrm{O}$ ataque propriamente dito aconteceu no dia 1 de julho de 1916. O violento ataque do exército de cem mil soldados (franceses e britânicos) deu início a longas e pesadas lutas, que se estenderam até novembro de 1916. Durante o primeiro dia de assalto, os britânicos perderam perto de 60 mil pessoas (especialmente das unidades voluntárias, formadas na Grã-Bretanha na onda do entusiasmo da guerra). Mais eficaz se mostrou o ataque do $6^{\circ}$ exército francês na região de Peronne, que conseguiu alcançar a maioria dos objetivos. Em setembro foi utilizada para a luta uma arma nova, até então desconhecida - os tanques ingleses - que, principalmente nos primeiros dias, deixaram nos alemães uma profunda impressão.

A batalha terminou no dia 18 de novembro de 1916. Após mais de quatro meses de lutas, os exércitos da Entente fizeram a frente avançar 12 quilômetros num trecho de quarenta quilômetros. As perdas de ambos os lados foram enormes: ingleses - mais de 400 mil, franceses - cerca de 200 mil, alemães - acima de 400 mil. As lutas nas margens do Somme não conseguiram paralisar a força combativa do exército alemão, mas sem dúvi- da enfraqueceram o moral dos soldados. $\mathrm{Nu}-$ merosos testemunhos confirmam que, após as vivências de 1916, o soldado alemão já não era o mesmo de 1914 ou 1915. O que Verdun foi para o soldado francês, Somme foi para o soldado alemão. Um eminente conhecedor da Primeira Guerra Mundial escreveu:

Da mesma forma que no início da guerra, em agosto e setembro de 1916, a primeira batalha do Marne foi o ponto crucial da invasão alemã, nos últimos meses da guerra, em julho de 1918, a segunda batalha de Marne foi o início da derrota alemã. ${ }^{9}$

Um grande mérito nessa vitória das forças aliadas coube a Ferdinand Foch (1851-1929), nomeado em maio de 1918 comandante-chefe dos exércitos coligados. O caráter, a coragem e a prontidão para assumir a responsabilidade foram por ele demonstrados já em março e maio de 1918, quando os alemães empreenderam mais uma ofensiva na frente ocidental. Eles conseguiram então deslocar a frente em 20-60 quilômetros em direção a Paris e, da distância de 100 quilômetros, iniciar o fogo contra a capital da França. Ferdinand Foch, partidário das ações ofensivas, conseguiu não apenas salvar a capital da França, mas passar ao contra-ataque. Um grande significado moral para os exércitos aliados teve $o$ fato de que se juntaram às lutas as primeiras divisões americanas, comandadas por John J. Pershing (18601948).

Sobre a influência dos exércitos americanos escreveu em suas memórias também Erich Ludendorff, o criador do plano da ofensiva alemã da primavera na frente ocidental. 
Não foi possível com as nossas vitórias induzir as nações da Coalizão à paz antes da chegada dos reforços americanos. A força do nosso exército não era suficiente para atingir de forma definitiva o inimigo, antes que se apresentasse o americano com significativas forças. Eu claramente me dava conta de que, em consequência disso, a nossa situação era muito séria. ${ }^{10}$

$\mathrm{O}$ ataque teve início no alvorecer do dia 18 de julho de 1918. Os exércitos franceses, apoiados por três divisões americanas, passaram à contraofensiva e desalojaram os alemães a mais ou menos dez quilômetros para trás. Foram feitos dez mil prisioneiros e tomadas algumas centenas de canhões. Teve uma grande participação nessa vitória, a utilização de 350 tanques, que precediam a infantaria que atacava e lhe abriam o caminho. Esse foi um momento crucial nas operações bélicas na frente ocidental. $\mathrm{O}$ ataque seguinte dos exércitos franceses e britânicos - comandados por Foch, nomeado marechal da França - trouxe novas vitórias. Os alemães sofreram uma derrota especialmente sensível no dia 8 de agosto, dia que Ludendorff reconheceu como o "dia negro do exército alemão na história dessa guerra"11. Nos combates de agosto, o exército alemão perdeu perto de 300 mil soldados. Igualmente, em setembro de 1918 os exércitos franceses, ingleses e americanos avançavam incessantemente, conquistando uma após outra as posições alemãs. No início de novembro de 1918, os alemães ainda se encontravam em terra francesa e belga, mas já se encontravam longe das posições ocupadas até o final de 1914.
As vitórias dos aliados fizeram com que no final de setembro o comando alemão começasse a exigir a imediata conclusão da paz com base nos 14 pontos do presidente dos Estados Unidos Woodrow Wilson (1856-1924). As negociações iniciadas pelo governo alemão com o objetivo de assinar o armistício coincidiram também no tempo com os acontecimentos revolucionários na Alemanha, que levaram à abdicação, no dia 9 de novembro, do imperador Guilherme II e ao final do II Reich Alemão. Já dois dias depois, no dia 11 de novembro de 1918, nas florestas de Compiègne, em Rethondes, foi assinado o armistício entre os aliados e a Alemanha. A derrota da Alemanha e dos outros Estados centrais devia, no entanto, ser carimbada pelo Tratado de Versalhes, cujas condições, impostas aos vencidos, deviam evitar a eclosão de um novo conflito em escala mundial, e aos vencedores dar a garantia de governar o mundo.

\section{Abstract}

World War First was the first modern total war. Differently to the earlier conflicts, where maneuver operations prevailed, now war operations lasted months or even years and produced millions of casualties. Armies needed more and more people, more and more weapons - and this could only be obtained at society's expense, so that war affected almost all families.

Keywords: World War First. Marne. Tannenberg. Jutland battle. Somme. Verdun. 


\section{Resumen}

La Primera Guerra Mundial fue la primera guerra total moderna. A diferencia de los conflictos anteriores, los cuales predominaron las maniobras de operaciones, ahora la guerra duró meses o incluso años y produjo millones de víctimas. Los anfitriones necesitan más y más personas, armas cada vez más - y esto sólo podría lograrse a expensas de la empresa, por lo que la guerra llegó a casi todas las familias.

Palabras clave: Primera Guerra Mundial. Marne. Tannenberg. Batalla de Jutlandia. Somme. Verdún.

\section{Notas}

1 Pierre MIQUEL. La Grande Guerre. Paris: Fayard, 1983, p. 136.

2 Die Aufzeichnungen des General-majors Max Hoffmann, t. 1, Verlag für Kulturpolitik. Berlin: Hrsg. von Karl Friedrich Nowak, 1929, p. 53.

3 Eugeniusz DE HENNING-MICHAELIS. Burza dziejowa. Pamiętnik z wojny światowej 1914-1917, t. 1. Warszawa: Gebethner i Wolff, 1928, p. 44.

4 Paul GUINN. British Strategy and Politics 1914 to 1918. Oxford: Clarendon Press, 1965, p. 55-57.

5 Ibidem, p. 60-62.

6 John KEEGAN. Jutland. MHQ: The Quarterly Journal of Military History, vol. I, n. 2: Winter 1989, p. 110-123.

7 Henry CORDA. Bitwa pod Verdun. Przasnysz: Wydawnictwo Forteca, 2004, p. 7-8.

8 LIDDELL HART, Basil Henry. History of the First World War. London: Pan Books Ltd., 1972, p. 303.

9 Janusz PAJEWSKI. Pierwsza wojna światowa 19141918. Warszawa: PWN, 2002, p. 706.

10 Erich LUDENDORFF. Meine Kriegserinnerungen 1914-1918. Berlin: Mitler und Sohn, 1919, p. 545.

11 Ibidem, p. 547.

\section{Referências}

BECKETT, Ian F. W. The Great War 1914-1918, 2. ed. Harlow: Pearson Education Limited, 2007.

CAMPBELL, John. Jutland: An Analysis of the Fighting. New York, 1998.

COPÉ, Jean-François-GUELTON, Frédéric. La bataille de la Marne. Paris: Tallandrier, 2013.

CORDA, Henry. Bitwa pod Verdun. Przasnysz: Wydawnictwo Forteca, 2004.

DENIZOT, Alain. Verdun, 1914-1918. Paris: Nouvelles Éditions Latines, 1996. . La Bataille de la Somme. Perrin, 2002.

Die Aufzeichnungen des General-majors Max Hoffmann, t. 1, Verlag für Kulturpolitik. Berlin: Hrsg. von Karl Friedrich Nowak, 1929.

FINDLEY, Carter V. Bureaucratic Reform in the Ottoman Empire: The Sublime Porte, 1789-1922. Princeton, New Jersey: Princeton University Press, 1980.

GILBERT, Martin. First World War. London: Harper-Collins, 1994.

GUINN, Paul. British Strategy and Politics 1914 to 1918. Oxford: Clarendon Press, 1965.

HALPERN, Paul G. A Naval History of World War I. Abingdon, 2003.

HENNING-MICHAELIS, Eugeniusz de. Burza dziejowa. Pamiętnik wojny światowej 19141917, t. 1. Warszawa: Gebethner i Wolff, 1928.

ISSELIN, Henri. La Bataille de la Marne. Paris: Arthaud, 1964.

KEEGAN, John. Jutland. MHQ: The Quarterly Journal of Military History, v. I, n. 2: Winter 1989, p. 110-123.

LIDDELL HART, Basil Henry. History of the First World War. London: Pan Books Ltd., 1972.

LUDENDORFF, Erich. Meine Kriegserinnerungen 1914-1918. Berlin: Mitler und Sohn, 1919. 
MACLEOD, Jenny. Reconsidering Gallipoli. Manchester, 2004.

MIQUEL, Pierre. La Grande Guerre. Paris: Fayard, 1983.

Les Oubliés de la Somme. Paris: Tallandrier, 2001.

OUSBY, I. The Road to Verdun: France, Nationalism and the First World War. London: Jonathan Cape, 2002.

PAJEWSKI, Janusz. Pierwsza wojna światowa 1914-1918. Warszawa: PWN. 2002.

MASSIE, Robert K. Castles of Steel: Britain, Germany, and the Winning of the Great War at Sea. New York, 2004.

TARRANT, V. E. Jutland: The German Perspective. A New View of the Great Battle, 31 May, 1916. London, 2001.

TETSURO, Sumida Jon. A Matter of Timing: The Royal Navy and the Tactics of Decisive Battle, 1912-1916. The Journal of Military History, 67 (1/2003), p. 85-136. 